\title{
Eficiência da adubação nitrogenada do tomateiro em duas épocas de cultivo
}

\author{
Magna Maria Macedo Ferreira ${ }^{1}$, Gilvan Barbosa Ferreira ${ }^{2}$, Paulo Cezar Rezende Fontes ${ }^{3}$
}

\begin{abstract}
RESUMO
A eficiência da adubação nitrogenada do tomateiro, na presença da adubação orgânica, foi avaliada em dois experimentos de campo conduzidos em duas épocas: primavera/verão (nov./98 a fev./99) e outono/primavera (maio/99 a out/99). Os dois experimentos foram instalados na horta da Universidade Federal de Viçosa, em solo da classe Argissolo Vermelho-Amarelo Câmbico. Em ambos, as doses de $\mathrm{N}$ aplicadas, na forma de nitrocálcio, foram 0,0; 93,3; 187,0; 374,0; e 748,0 kg/ha, e as doses de adubação orgânica, na forma de esterco bovino curtido, foram 0 e 8 t/ha de matéria seca. Os experimentos seguiram o delineamento em blocos ao acaso, no arranjo fatorial 5 x 2 , com quatro repetições. O peso e o número de frutos comercializáveis de tomate, por planta, são aumentados com o aumento do nível de $\mathrm{N}$ no solo. A percentagem de frutos comercialmente desclassificáveis é maior na primavera/verão do que no outono/primavera. A eficiência da adubação nitrogenada pelo tomateiro é maior no outono/primavera do que na primavera/verão. Na primavera/verão ela foi maior quando não houve adição de matéria orgânica ao solo, o contrário ocorrendo no outono/primavera.
\end{abstract}

Palavras-chave: Lycopersicon esculentum, Mill. tomate, nitrogênio, adubaçdo orgânica, esterco bovino.

\begin{abstract}
Nitrogen fertilization efficiency in tomato at two sowing times

Nitrogen fertilization efficiency of the tomato crop, with organic fertilization, was evaluated in two experiments conducted at two times: spring/summer and autumn/spring. The experiments were carried out at the horticulture experimental field of the Universidade Federal de Viçosa in a Cambic Red-Yellow Argisol. In both times, the applied $\mathrm{N}$ doses, in the form of nitrocalcium, were $0.0,93.3,187.0,374.0$ and $748.0 \mathrm{~kg} / \mathrm{ha}$ and the doses of organic fertilization, in the form of cattle manure compost, were 0 and $8 \mathrm{t} /$ ha of dry matter. The experiments were arranged in randomized blocks, in a $5 \times 2$ factorial design, with four replications. The weight and the number of marketed tomatoes per plant increased with the increase of $\mathrm{N}$ level in the soil. The percentage of commercially discarded fruits was larger in the spring/summer than in the autumn/spring. The nitrogen fertilization efficiency in tomato crop is higher in the autumn/ spring than in the spring/summer. In the spring/summer, the efficiency was higher without the addition of organic matter to the soil, whereas in the autumn/spring the opposite took place.
\end{abstract}

Key words: Lycopersicon esculentum, Mill. tomato, nitrogen, organic fertilization, cattle manure.

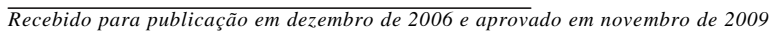

Engenheira Agrônoma, Doutora. Universidade Federal de Roraima, Centro de Ciências Agrárias, Campus do Cauamé, Departamento de Fitotecnia, BR 174, Km 12, Monte Cristo, 69300-000, Boa Vista, Roraima, Brasil. magna.m.m.ferreira@bol.com.br

2 Engenheiro Agrônomo, Doutor. Empresa Brasileira de Pesquisa Agropecuária, Centro de Pesquisa Agroflorestal de Roraima, Embrapa Roraima, BR 174, km 08, Distrito Industrial, 69301-970, Boa Vista, Roraima, Brasil. gilvan@cpafrr.embrapa.br

3 Engenheiro Agrônomo, Ph. Doctor. Universidade Federal de Viçosa, Departamento de Fitotecnia, Av. Peter Henry Rofls s/n, Campus Universitário, 36570-000, Viçosa, Minas Gerais, Brasil.pacerefo@ ufv.br
} 


\section{INTRODUÇÃ̃O}

O crescimento e a produção do tomateiro e de outras culturas de importância econômica dependem, além de outros fatores, de adequado suprimento de nutrientes pelo solo às plantas. Sendo assim, para se obter alta produção de frutos comercializáveis no tomateiro é necessário conhecer os seus requerimentos nutricionais (Gomez-Lepe \& Ulrich, 1974). Levando-se em conta os processos fisiológicos das plantas, o nitrogênio, comparado com os outros nutrientes, tem maior efeito sobre as taxas de crescimento e absorção de outros nutrientes, sendo, portanto, mais importante em termos de controle da nutrição ótima das culturas (Huett \& Dettmann, 1988).

$\mathrm{O}$ crescimento e a produção em resposta ao $\mathrm{N}$ têm sido bastante pesquisados em muitas espécies vegetais cultivadas e algumas silvestres. No tomateiro, a elevação no nível de $\mathrm{N}$ fornecido às plantas aumenta o peso de matéria seca das raízes, do caule, das folhas e dos frutos, a altura da planta, o número de folhas, a área foliar, o florescimento, a frutificação e a produtividade. Em condições de campo, a nutrição ótima dessa cultura pode ser alcançada quando a quantidade aplicada de fertilizantes nitrogenados for igual à alta demanda que ocorre durante o período de crescimento dos frutos (Huett \& Dettmann, 1988, Singh \& Sharma, 1999).

Suprimento inadequado de $\mathrm{N}$ no começo da fase reprodutiva do tomateiro, ou seja, durante o desenvolvimento da primeira inflorescência, traz consequências imediatas ao crescimento e desenvolvimento da planta, reduzindo as taxas de expansão foliar e de crescimento da parte aérea. Tal escassez ainda provoca nas folhas síntese de polifenóis, os quais inibem os reguladores do crescimento, a coloração amarelada e o aumento na quantidade de amido nos cloroplastos, demonstrando que o metabolismo é profundamente modificado. A rápida resposta do tomateiro é devido à pequena reserva de $\mathrm{N}$ durante o período de desenvolvimento da primeira inflorescência (Quijada et al., 1992).

As exigências nutricionais do tomateiro podem ser supridas pela adição ao solo de fertilizante químico, de matéria orgânica ou de ambos. A produção de frutos é possível com a prática alternativa de fertilização do solo com matéria orgânica (Rahman et al., 1997; Hunter \& Tuivavalagi, 1998), devido à alta concentração de $\mathrm{N}$ normalmente presente na mesma (Atiyeh et al., 2000). A disponibilidade de $\mathrm{N}$ para as plantas depende da taxa de mineralização da matéria orgânica, que vai depender da quantidade de $\mathrm{N}$ imobilizado disponível na mesma; da temperatura, da umidade, do $\mathrm{pH}$ e da aeração do solo; das perdas do $\mathrm{N}$ por lixiviação e da razão C:N do material. É ainda constatado no tomateiro que os valores mais altos de produtividade são obtidos quando se adiciona $\mathrm{N}$ mi neral à matéria orgânica (Salek et al., 1981; Francis \& Cooper, 1998). Há grande variação na quantidade de $\mathrm{N}$ recomendada para a cultura do tomateiro, não considerando variações existentes nas épocas do ano.

O tomateiro, devido à sua importância econômica, é explorado em ampla faixa de condições climáticas. No entanto, para que os rendimentos sejam ótimos, essa cultura tem requerimentos específicos. Na região Sudeste, emaltitudes em torno de $600 \mathrm{~m}$, as melhores produções são obtidas na época do ano em que a precipitação e a temperatura são mais baixas, normalmente no período de outono/primavera. A chamada "época não ótima" caracterizase por elevadas temperatura, umidade relativa, radiação solar e precipitação pluviométrica, condições consideradas adversas ao cultivo do tomateiro, por favorecer o desenvolvimento de pragas e doenças; acelerar os processos de respiração, floração e formação dos frutos (Sam \& Iglesias, 1994); causar desenvolvimento vegetativo reduzido; aumentar a taxa de abortos florais; e produzir frutos de baixa qualidade, diminuindo, dessa forma, os rendimentos econômicos das semeaduras dessa época (Domini et al., 1993). Este periodo do ano também causanos tecidos do tomateiro decr6scimo nos teores de $\mathrm{N}$, aminoácidos e proteínas e aumento nos teores de prolina, indicando estresse ambiental (Supatra et al., 1998). Talveznessa época do ano a quantidade de $\mathrm{N}$ deva ser diferente da utilizada na época mais favorável.

Diante do exposto, o objetivo deste trabalho foi avaliar os efeitos de doses de nitrogênio e da adubação orgânica sobre a eficiência da adubação nitrogenada nas plantas de tomateiro em duas épocas de plantio: primavera/ verão e outono/primavera.

\section{MATERIAL E MÉTODOS}

Foram conduzidos dois experimentos, em duas épocas: o primeiro na primavera/verão e o segundo no outono/primavera. Eles foram instalados em áreas localizadas na horta da Universidade Federal de Viçosa.

O experimento de primavera/verão foi conduzido no campo no período de 13 de novembro de 1998 a 11 de fevereiro de 1999. O de outono/primavera entre 14 de maio e 27 de outubro de 1999 .

Os dados de temperatura, umidade relativa do ar e precipitação de Viçosa durante o período de condução dos experimentos de primavera/verão e de outono/primavera, obtidos na estação principal de meteorologia do Departamento de Engenharia Agrícola da Universidade Federal de Viçosa, encontram-se nas Tabelas 1 e 2, respectivamente.

Os dois experimentos foram realizados em solo da classe Argissolo Vermelho-Amarelo Câmbico (Tabelas 3 e 4), em duas áreas distintas. As amostras de solo foram retiradas antes da aplicação dos tratamentos. 
Tabela 1. Temperatura e umidade relativa do ar e quantidade total de chuva (precipitação) durante os meses de condução do experimento de primavera/verão $(1998 / 1999)^{1}$

\begin{tabular}{|c|c|c|c|c|c|}
\hline \multirow{3}{*}{$\begin{array}{c}\text { Mês de } \\
\text { observação }\end{array}$} & \multicolumn{3}{|c|}{ Temperaturas } & \multirow{3}{*}{$\begin{array}{c}\text { Umidade relativa } \\
\%\end{array}$} & \multirow{3}{*}{$\begin{array}{c}\text { Precipitação } \\
\text { mm }\end{array}$} \\
\hline & Mínima & Média & Máxima & & \\
\hline & & ${ }_{\mathrm{o}} \mathbf{C}$ & & & \\
\hline Nov./98 & 17,0 & 20,4 & 26,0 & 84,7 & 216,9 \\
\hline Dez./98 & 18,3 & 22,4 & 28,9 & 82,5 & 105,3 \\
\hline Jan./99 & 18,9 & 22,4 & 30,3 & 78,3 & 154,2 \\
\hline Fev./99 & 18,4 & 21,9 & 29,9 & 78,1 & 88,1 \\
\hline Média & 18,2 & 21,8 & 28,8 & 80,9 & 141,1 \\
\hline D. padrao & 0,8 & 0,9 & 1,9 & 3,2 & 57,8 \\
\hline Total & - & - & - & - & 564,5 \\
\hline
\end{tabular}

' Dados obtidos da estação principal de meteorologia do Departamento de Engenharia Agrícola da Universidade Federal de Viçosa.

Tabela 2. Temperatura e umidade relativa do ar e quantidade total de chuva (precipitação) durante os meses de condução do experimento de outono/primavera (1999) ${ }^{1}$

\begin{tabular}{|c|c|c|c|c|c|}
\hline \multirow[b]{2}{*}{$\begin{array}{c}\text { Mês de } \\
\text { observação }\end{array}$} & \multicolumn{3}{|c|}{$\begin{array}{c}\text { Temperaturas } \\
\text { oC }\end{array}$} & \multirow[b]{2}{*}{$\begin{array}{c}\text { Umidade relativa } \\
\%\end{array}$} & \multirow[b]{2}{*}{$\begin{array}{c}\text { Precipitação } \\
\text { mm }\end{array}$} \\
\hline & Mínima & Média & Máxima & & \\
\hline Mai./99 & 11,7 & 16,4 & 25,3 & 80,2 & 2,0 \\
\hline Jun./99 & 11,5 & 16,1 & 24,5 & 82,8 & 13,2 \\
\hline Jul./99 & 12,4 & 16,4 & 24,4 & 81,8 & 4,2 \\
\hline Ago./99 & 8,9 & 14,8 & 25,9 & 71,8 & 0,0 \\
\hline Set./99 & 12,8 & 17,3 & 27,1 & 67,0 & 50,7 \\
\hline Out./99 & 14,7 & 17,6 & 25,0 & 74,6 & 118,0 \\
\hline Média & 12,0 & 16,4 & 25,4 & 76,4 & 31,4 \\
\hline D. padrao & 1,9 & 1,0 & 1,0 & 6,3 & 46,5 \\
\hline Total & - & - & - & - & 188,1 \\
\hline
\end{tabular}

Dados obtidos da estação principal de meteorologia do Departamento de Engenharia Agrícola da Universidade Federal de Viçosa.

Tabela 3. Características químicas das amostras dos solos utilizados nos dois experimentos

\begin{tabular}{|c|c|c|c|c|c|c|c|c|c|c|}
\hline \multirow[t]{4}{*}{ Experimento } & \multicolumn{10}{|c|}{ Características químicas } \\
\hline & \multicolumn{3}{|c|}{$\mathbf{N}_{\text {mineral }}{ }^{\top}$} & $\mathbf{P}$ & $\mathbf{K}^{+}$ & \multicolumn{5}{|c|}{$\mathrm{Ca}^{2+} \mathrm{Mg}^{2+} \mathrm{Al}^{3+} \mathrm{H}+\mathrm{Al} \mathrm{pH}$} \\
\hline & $0-20 \mathrm{~cm}$ & $20-40 \mathrm{~cm}$ & $40-60 \mathrm{~cm}$ & \\
\hline & & kg/ha & & \multicolumn{7}{|c|}{$\frac{0-20 \mathrm{~cm}}{\mathrm{cmol}_{\mathrm{c}} / \mathrm{dm}^{3}}$} \\
\hline Primavera/verao & 39,81 & - & - & 21 & 51 & 0,9 & 0,0 & 0,3 & 3,3 & 4,3 \\
\hline Outono/primavera & 24,62 & 15,04 & 13,12 & 86 & 85 & 0,9 & 0,0 & 0,3 & 3,3 & 5,8 \\
\hline
\end{tabular}

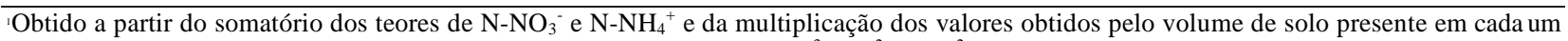

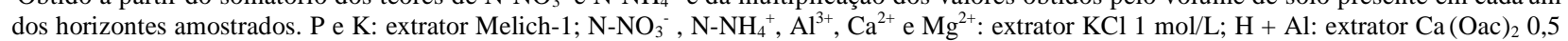
mol/L a pH 7,0; e pH em água, relação 1:2,5.

Nos dois experimentos, os tratamentos foram constituídos de cinco doses de nitrogênio, em presença ou não de adubação orgânica. Foram testadas as doses de N correspondentes a 0,$0 ; 93,3 ; 187,0 ; 374,0 ;$ e 748,0 kg/ha. A fonte desse nutriente foi o nitrocálcio. As doses de matéria orgânica foram 0 e 8 t/ha de matéria seca de esterco bovino curtido. A caracterização química do adubo orgânico colocado nos dois experimentos encontra-se na Tabela 5 . Os tratamentos foram distribuídos no delineamen-

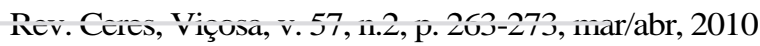

to em blocos ao acaso, com quatro repetições, perfazendo 40 parcelas.

Sementes de tomate cv. Santa Clara foram semeadas em copos de jornal conterão substrato esterilizado, na densidade de duas sementes por copo, nos experimentos de primavera/verão e outono/primavera, respectivamente. As mudas foram transplantadas nos respectivos experimentos, no espaçamento de $1,0 \mathrm{~m}$ entre fileiras e $0,5 \mathrm{~m}$ entre plantas, no total de 28 plantas por parcela (quatro 
fileiras com sete plantas cada), sendo consideradas úteis as 10 plantas centrais da parcela. As dimensões de cada parcela foram $4 \mathrm{~m}$ de largura e $3,5 \mathrm{~m}$ de comprimento, ocupando área total de $14 \mathrm{~m}^{2}$, sendo $5^{\mathrm{m} 2}$ de área útil.

Em função da análise do solo, foi determinada a necessidade de calagem dos experimentos, que foi realizada nos experimentos aplicando-se calcário dolomítico (PRNT $=100 \% ; 38,16 \%$ de $\mathrm{CaO}$ e $14 \%$ de $\mathrm{MgO}$ ), a lanço, de forma a elevar para $70 \%$ a saturação de bases, fazendo-se a sua incorporação por meio de uma aração e duasgradagens.

Depois dos solos preparados, foram aplicadas, nos sulcos, as adubações de transplante, as quais constaram da aplicação de $100 \mathrm{~kg} /$ ha de $\mathrm{P}_{2} \mathrm{O}_{5}$ na forma de superfosfato simples, $250 \mathrm{~kg} / \mathrm{ha}$ de sulfato de magnésio, $10 \mathrm{~kg} / \mathrm{ha}$ de bórax, $15 \mathrm{~kg} / \mathrm{ha}$ de sulfato de zinco e $0,5 \mathrm{~kg} / \mathrm{ha}$ de molibidato de amônio. Foi incorporado o inseticida de solo Carbofuran na dose recomendada pelo fabricante.

As doses de $\mathrm{N}$ foram parceladas da seguinte maneira: $10 \%$ no momento do transplante, nos sulcos, e $15 \%$ aos 21, 35, 49, 63, 77 e 91 dias após o transplante (DAT), em cobertura, ao lado das plantas, em meia-lua. A dose de $\mathrm{K}_{2} \mathrm{O}(250 \mathrm{~kg} / \mathrm{ha})$ foi parcelada na mesma proporgdo do $\mathrm{N}$, utilizando-se o cloreto de potássio.

Nos dois experimentos, o tomateiro foi conduzido em haste única, com tutoramento em cerca cruzada, tendo sido as plantas podadas três folhas acima da sexta inflorescência. As irrigações por sulco foram realizadas quando necessárias, em complementação ao volume de água precipitado pelas chuvas.

Os frutos foram colhidos quando a coloração estava avermelhada no experimento de primavera/verão e cor de cana no de inverno/primavera, devido ao ataque de pardais nesse período do ano no local. As colheitas foram realizadas nas seguintes datas:

Tabela 4. Granulometria das amostras de solos dos experimentos

\begin{tabular}{lccc}
\hline & \multicolumn{3}{c}{ Fração textural } \\
\cline { 2 - 4 } Experimento & Argila & Silte & Areia \\
\cline { 2 - 4 } & \multicolumn{3}{c}{} \\
\hline Primavera/verão & 50 & 16 & 34 \\
Outono/primavera & 51 & 12 & 37 \\
\hline
\end{tabular}

Experimento de primavera/verão: aos 62, 67, 72, 80 e 88 dias após o transplantio.

Experimento de outono/primavera: aos 94, 100, 106, $112,119,127,134,142,151$ e 163 dias após o transplantio.

Nos dois experimentos, os frutos sem defeitos foram classificados de acordo com o diâmetro transversal. Foi considerado como produção de frutos extras o somatório dos pesos dos frutos das quatro primeiras classes e como produção comercial o somatório dos pesos dos frutos das seis primeiras classes. Apesar de as classes médio especial e pequeno geralmente não serem comercializadas nas centrais de abastecimento, a legislação brasileira as classifica como comerciais, aplicando-se bem à época de condução do experimento de primavera/verão, visto ser a época de menor oferta de tomate de qualidade. A produção não-comercial de frutos correspondeu ao somatório dos pesos dos frutos com diâmetro $40 \mathrm{~mm}$ (refugo) e dos frutos desqualificados devido à ocorrência de podridão-apical, broca, rachaduras, Alternaria solani e outras anomalias. A produção total foi obtida pelo somatório das produções comercial e não-comercial.

Foi calculada também a produção ponderada ou equivalente dos frutos extra AA (PEAA), utilizando-se os fatores de ponderação de 1,000; 0,625; e 0,375, baseando-se nos pregos das classes extra AA (US\$ 4,37/cx), extra A (US\$ 2,73/cx) e extra (US\$ 1,64/cx) do tomate tipo Santa Cruz, comercializado em caixa tipo $\mathrm{K}$, obtidos no mês de junho de 2000 na CEASA de Belo Horizonte (CEASA, 2000).

Calculou-se o incremento relativo na produtividade advindo da adubação nitrogenada (IRPAN), visando estabelecer o acréscimo obtido na PEAA por kg de $\mathrm{N}$ aplicado. Para tal, utilizou-se a diferença entre as produções equivalentes a frutos extra AA (PEAA) estimadas com a dose de $\mathrm{N}$ para a máxima eficiência física (MEF) e com a dose zero,e a diferença entre elas, por meio da seguinte fórmula:

\section{PEAA com a dose de MEF - PEAA na dose zero IRPAN $=-1$ Dose de MEF - Dose zero}

Em que: PEAA expressa em $\mathrm{kg} / \mathrm{ha}$ de frutos; dose de MEF de $\mathrm{N}$ expressa em $\mathrm{kg} / \mathrm{ha}$; e IRPAN expresso em $\mathrm{kg}$ de frutos extras $\mathrm{AA} / \mathrm{kg}$ de $\mathrm{N}$ aplicado.

Tabela 5. Teores de umidade, de matéria orgânica (M.O.) e de nutrientes na matéria seca dos estercos bovinos utilizados nos dois experimentos

\begin{tabular}{|c|c|c|c|c|c|c|c|}
\hline \multirow[t]{2}{*}{ Experimento } & Umidade & M.O. & $\mathbf{N}_{1}$ & $\mathbf{P}$ & $\mathbf{K}_{2}$ & $\mathbf{C a}^{2}$ & $\mathbf{M g}^{2}$ \\
\hline & \multicolumn{2}{|c|}{$\%$} & \multicolumn{5}{|c|}{ dag/kg } \\
\hline Primavera/verão & 44 & 22,16 & 1,63 & 1,20 & 2,81 & 3,18 & 1,83 \\
\hline Outono/primavera & 17 & 49,45 & 2,06 & 0,84 & 2,35 & 0,83 & 0,57 \\
\hline
\end{tabular}

Extraído com ${ }_{\mathrm{H} 2 \mathrm{SO} 4}$ concentrado.

${ }^{2}$ Extração nitricoperclórica 3:1. 
Os dados obtidos foram submetidos à analise de variância e de regressão, e foram ajustados relacionandose as variáveis dependentes às doses de $\mathrm{N}$ aplicadas emcada dose de matéria orgânica. Os modelos de regressãotestados foram: lineares, quadráticos e raizquadráticos. Escolheu-se o modelo com base no significado biológico, na significância dos coeficientes de regressão até $10 \%$ deprobabilidade, pelo teste t, e no maior coeficiente de determinação.

A dose de $\mathrm{N}$ que proporcionou a máxima produção física equivalente a frutos extra AA (produção de máxima eficiência física $=\mathrm{MEF}$ ) foi obtida igualando-se a primeira derivada da equação correspondente à produção equivalente a frutos extra AA (PEAA) ao valor zero. A dose de $\mathrm{N}$ que proporcionou a máxima eficiência econômica (máximo retorno econômico $=\mathrm{MEE}$ ) foi obtida igualando-se a primeira derivada da equação correspondente a PEAA a 0,004619953, correspondente à relação entre os pregos do nitrogênio (US\$ 0,92/kg) e do tomate extra AA (US\$ 198,71/ t) obtidos no mês de junho de 2000 na CEASA de Belo Horizonte (CEASA, 2000).

\section{RESULTADOS E DISCUSSÃO}

\section{Experimento de primavera/verão}

$\mathrm{O}$ aumento da dose de $\mathrm{N}$ não alterou os pesos médios dos frutos das produções total e extra, sem ou com adição de matéria orgânica ao solo, os quais permaneceram constantes. Já os pesos médios dos frutos da produção comercial, sem ou com adição de matéria orgânica, foram linearmente aumentados (Tabela 6), concordando com os resultados de Adams et al. (1973), os quais constataram o aumento no peso médio dos frutos comercializáveis com a aplicação de N. Como a elevaçãodo suprimento de nitrogênio às plantas causa aumentono seu potencial fotossintético, é de se esperar maior produção de esqueletos carbônicos nas folhas, aumentando-se o potencial da fonte e, consequentemente, o suprimento ao dreno, representado pelos frutos de tomate. Dessa forma, espera-se que haja aumento no peso médio dos frutos de tomateiro com o aumento na taxa de fertilização nitrogenada. Ainda na Tabela 6, pode-se observar que a aplicação de $\mathrm{N}$ aumentou o número de frutos das produções total, comercial e extra de frutos de tomate, sem ou com adição de matéria orgânica ao solo. Adams et al. (1973) também encontraram aumento no número de frutos comerciais por planta e, consequentemente, na produtividade comercial do tomateiro com a aplicação de N. Felipe \& Casanova (2000) constataramque o aumento no teor de $\mathrm{N}$ no solo aumentou a produção total do tomateiro não devido ao aumento no pesomédio dos frutos, mas sim no número de frutos por planta. Essas respostas, encontradas em diferentes pesquisas, possivelmente estão relacionadas ao equilíbrio hormonal na parte aérea da planta. É sabido que o aumento na disponibilidade de nitrogênio às plantas aumenta a síntese do hormônio giberelina (GA) no apice dos brotos e nas folhas em expansão. Esse hormônio aumenta a frutificação (crescimento inicial do fruto seguinte à polinização) e o crescimento dos frutos.

Independentemente da adição de matéria orgânica no solo, as produções das classes extra AA, extra A e média extra foram influenciadas pela adubação nitrogenada, tendo a produção extra AA aumentado linearmente com as doses de $\mathrm{N}$ e as produções extra A e média extra alcançaram os valores máximos 18,29 e 3,04 t/ha com as doses 326,6 e $225,9 \mathrm{~kg} / \mathrm{ha}$ de $\mathrm{N}$, respectivamente. Com a adição de esterco, as produções de frutos extra AA e extra A alcançaram os valores máximos, 1,87 e 19,19 t/ha, com as doses 469,2 e 511,4 kg/ha de N, respectivamente (Figura 1). A maior proporção da produção extra nas duas doses de matéria orgânica foi dos frutos tipo extra A (Tabela 7). Tais produções máximas estão aquém daquelas encontradas por Guimarães (1998) para essas classes em condições de campo. Os frutos extra AA, extra A e médio extra tiveram, respectivamente, pesos médios de 193,50; 137,74; e 94,92 g/fruto, sem adição de matéria orgânica, e de 173,36;137,00; e 111,33 g/fruto, com adição. Estes valores são superiores aos encontrados por Fayad (1998) em condições de campo com o mesmo cultivar testado no presente experimento (Santa Clara), os quais foram 135, 92 e 71 para as classes extra AA, extra A e extra, respectivamente, indicando maior alocação de fotoassimilados para os frutos sem que houvesse uma concomitante alocação de água, talvez pelo menor número de frutos por planta no presente experimento.

Houve alta percentagem de frutos comercialmente desclassificáveis em todas as doses de $\mathrm{N}$ nos dois níveis de matéria orgânica (Tabela 8), o que se deve às condições climáticas reinantes nessa época do ano, primavera/ verão (Tabela 1), as quais favoreceram as pragas e doenças. Essas produções atingiram valores superiores aos encontrados por Guimarães (1998). Os principais fatores responsáveis pela desclassificação de frutos foram os defeitos causados pelos ataques de broca e a ocorrência de Alternaria solani.

Houve também ocorrência de podridão-apical, de rachaduras e de frutos de diâmetro menor que $40 \mathrm{~mm}$ ou refugos, além de outras anomalias (Tabela 8). A podridão apical foi relativamente maior no tratamento com $374 \mathrm{~kg} /$ ha de $\mathrm{N}$ e $8 \mathrm{t} /$ ha de matéria orgânica e na dose $748 \mathrm{~kg} / \mathrm{ha}$ de $\mathrm{N}$ nos dois níveis de adubação orgânica (Tabela 8). A podridão-apical é um distúrbio de ordem fisiológica que tem como causa principal alterações no estado nutricional do tomateiro, comprometendo seriamente a produçãocomercializável dos seus frutos. A deficiência de cálcio na 
Tabela 6. Equações de regressão relacionando o peso médio (PM) e o número de frutos (NF) das produções extra, comercial e total com as doses de $\mathrm{N}$ aplicadas, sem e com adição de matéria orgânica ao solo, do experimento de primavera/verão

\begin{tabular}{|c|c|c|c|}
\hline MO (t/ha) & Característica & Equação de regressão & $\mathbf{R}_{2}$ \\
\hline & \multicolumn{3}{|c|}{ Produção extra } \\
\hline 0 & $\mathrm{PM}$ (g/fruto) & $\hat{\mathrm{Y}}=\overline{\mathrm{Y}}=135,08$ & - \\
\hline 8 & $\mathrm{PM}$ (g/fruto) & $\hat{\mathrm{Y}}=\overline{\mathrm{Y}}=139,64$ & - \\
\hline 0 & $\mathrm{NF}(\mathrm{n} / \mathrm{ha})$ & $\hat{\mathrm{Y}}=77.762,0+10.131,6^{* * *} \mathrm{X}^{0,5}-266,049^{* *} \mathrm{X}$ & 0,9510 \\
\hline \multirow[t]{2}{*}{8} & $\mathrm{NF}(\mathrm{n} \% \mathrm{ha})$ & $\hat{\mathrm{Y}}=105.979+429,170^{* \cdots *} \mathrm{X}-0,491341^{* * *} \mathrm{X}^{2}$ & 0,9942 \\
\hline & \multicolumn{3}{|c|}{ Produção comercial } \\
\hline 0 & PM (g/fruto) & $\hat{\mathrm{Y}}=117,041+0,0329005^{\circ} \mathrm{X}$ & 0,6433 \\
\hline 8 & PM (g/fruto) & $\hat{\mathrm{Y}}=117,752+0,0319425^{\circ} \mathrm{X}$ & 0,3903 \\
\hline 0 & $\mathrm{NF}\left(\mathrm{n}^{\circ} / \mathrm{ha}\right)$ & $\hat{\mathrm{Y}}=96.934,9+10.276,7^{* * * *} \mathrm{X}^{0.5}-269,792^{* *} \mathrm{X}$ & 0,9032 \\
\hline \multirow[t]{2}{*}{8} & $\mathrm{NF}\left(\mathrm{n}^{\circ} / \mathrm{ha}\right)$ & $\hat{\mathrm{Y}}=134.087+441,301^{\cdots \cdots} \mathrm{X}-0,518147^{\cdots \cdots} \mathrm{X}^{2}$ & 0,9897 \\
\hline & \multicolumn{3}{|c|}{ Produção total } \\
\hline 0 & PM (g/fruto) & $\hat{\mathrm{Y}}=\overline{\mathrm{Y}}=108,04$ & \\
\hline 8 & PM (g/fruto) & $\hat{\mathrm{Y}}=\overline{\mathrm{Y}}=108,19$ & \\
\hline \multirow{2}{*}{0} & $\mathrm{NF}\left(\mathrm{n}^{\circ} / \mathrm{ha}\right)$ & $\hat{\mathrm{Y}}=220.170+17.204 .7^{* * *} \mathrm{X}^{0,5}-400.919^{* *} \mathrm{X}$ & \\
\hline & 8 & $\mathrm{NF}(\overline{\mathrm{n}} \mathrm{o} A \mathrm{ha}) \cdot 983+477,371^{* *} \mathrm{X}-0,440367^{*} \mathrm{X}^{2}$ & \\
\hline
\end{tabular}
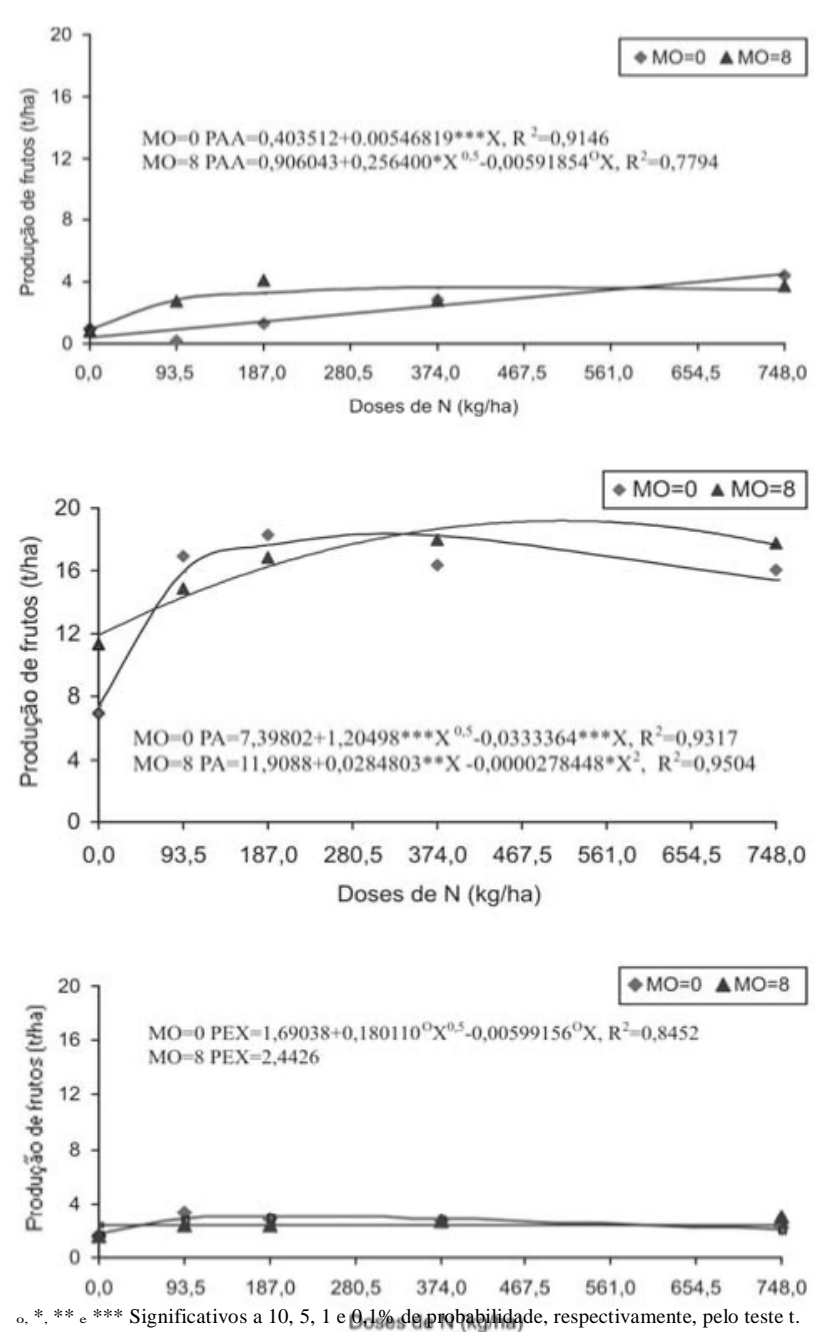

Figura 1. Produções de frutos extra AA (PAA), extra A (PA) e médio extra (PEX) em função das toses de nitrogênio $(\mathrm{N})$ e da matéria orgânica $(\mathrm{MO})$ do experimento de primavera/verão. porção apical do fruto é a causa primária dessa anomalia (Castellane, 1988). O desequilíbrio nutricional na planta, relacionado ao distúrbio, é favorecido por circunstâncias ou fatores predisponentes. Assim, pode ocorrer excesso de sais solúveis na solução do solo, especialmente sais de potássio, magnésio e sódio. Isso acarreta a absorção deficiente de $\mathrm{Ca}$, mesmo quando há teor adequado no solo. A razão é que à medida que a concentração total de sais solúveis se torna excessiva, decrescem a solubilidade e a atividade dos sais de Ca numa razão mais alta em relação aos outros sais. Tais condições são desvantajosas à absorção de $\mathrm{Ca}$, em relação aos demais pelo tomateiro (Wilcox et al.,1973; Bar-Tal \& Pressman, 1996; Belda et al., 1996).

Outras causas predisponentes frequentemente relacionadas com a podridão-apical têm sido a deficiência de água na planta e no solo e o suprimento excessivo de nitrogênio, o qual pode provocar crescimento vigoroso na planta e, consequentemente, aumentar a taxa transpiratória (Kirkby, 1979). Dessa forma, a maior ocorrência de podridão-apical nos tratamentos com maiores disponibilidades de $\mathrm{N}$ no solo pode ter sido devido à maior biomassa da planta, causando maior taxa de transpiração. Também pode ter ocorrido maior salinização do solo em decorrência das altas doses de fertilizantes nitrogenados aplicadas, as quais decrescem a absorção de Ca e aumentam a ocorrência de podridão-apical (Hohjo et al., 1995). Em solos muito salinizados o $\mathrm{Ca}^{2+}$ não consegue ser absorvido pelas raízes na mesma magnitude que os demais íons, ou seja, perde na concorrência pelos sítios de absorção, problema que não pode ser resolvido nem com uma calagem regular. 
Tabela 7. Produção de frutos extra AA, extra A, médio extra e não-comerciais em função das doses de nitrogênio e da adubação orgânica do experimento de primavera/verão

\begin{tabular}{lccc}
\hline & & \multicolumn{2}{c}{ Adubação orgânica (t/ha) } \\
\cline { 1 - 1 } Koses de N & Classes de frutos & $\mathbf{0}$ & $\mathbf{8}$ \\
\cline { 3 - 4 } 0,0 & & Produção de frutos (kg/ha) \\
0,0 & Extra AA & 929 & 820 \\
$\subseteq 0$ & Extra A & 6.978 & 11.318 \\
0,0 & Médio extra & 1.595 & 1.627 \\
93,5 & Não-comercial & 11.447 & 14.056 \\
93,5 & Extra AA & 201 & 2.738 \\
93,5 & Extra A & 16.942 & 14.883 \\
93,5 & Médio extra & 3.270 & 2.432 \\
187,0 & Não-comercial & 15.846 & 15.134 \\
187,0 & Extra AA & 1.287 & 4.097 \\
187,0 & Extra A & 18.282 & 16.864 \\
187,0 & Médio extra & 2.803 & 2.405 \\
374,0 & Não-comercial & 18.165 & 13.127 \\
374,0 & Extra AA & 2.855 & 2.799 \\
374,0 & Extra A & 16.347 & 17.971 \\
374,0 & Médio extra & 2.770 & 2.743 \\
748,0 & Não-comercial & 19.507 & 18.428 \\
748,0 & Extra AA & 4.414 & 3.731 \\
748,0 & Extra A & 16.075 & 17.760 \\
748,0 & Médio extra & 2.224 & 3.005 \\
\hline & Não-comercial & 19.784 & 18.914 \\
\hline
\end{tabular}

Tabela 8. Valores absolutos e relativos das produções total e não-comercial de frutos de tomate em função das doses de $\mathrm{N}$ e da adubação orgânica (MO) do experimento de primavera/verão

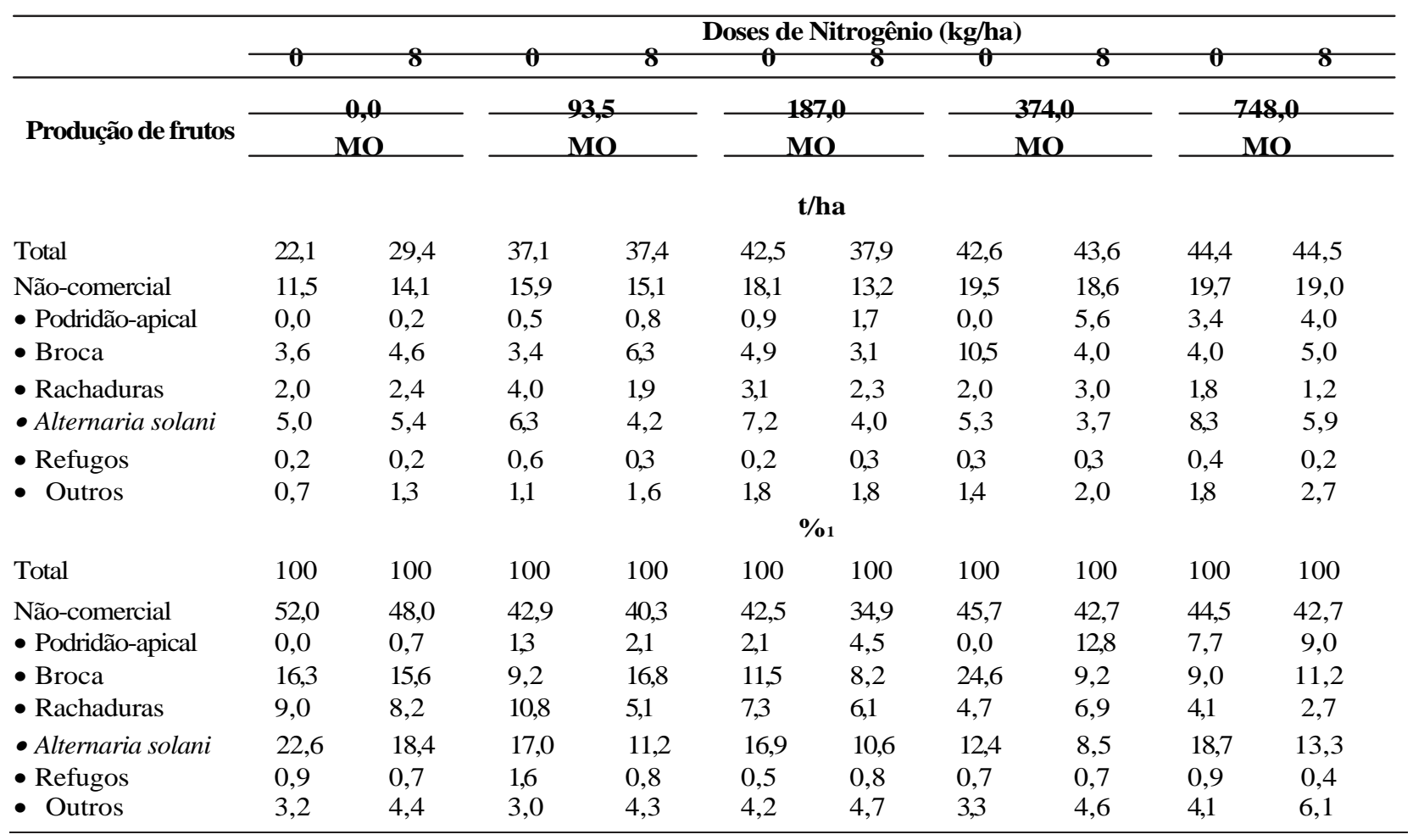

'Em relação à produção total. 
$O$ incremento relativo na produtividade resultante da adubação nitrogenada (IRPAN), no experimento de primavera/verão, foi 15,23 e 13,22 kg de frutos extra AA por $\mathrm{kg}$ de $\mathrm{N}$ aplicado nas doses 0 e 8 t/ha de matéria orgânica, respectivamente. A baixa eficiência da adubação nitrogenada pode estar associada às elevadas precipitações ocorridas na primavera/verão, durante o ciclo da cultura, e ao modo de aplicação da água, por superfície, e do fertilizante, em forma granulada, em cobertura, ocasionando percolação do adubo. Também pode ter havido lixiviação do $\mathrm{N}^{-\mathrm{NO}_{3}}{ }^{-}$para as camadas mais profundas do solo. Guimarães (1998) encontrou valores de IRPAN variando de 35,7 a $111,6 \mathrm{~kg}$ de frutos extra AA por $\mathrm{kg}$ de $\mathrm{N}$ aplicado, dependendo do local de plantio, da estufa, do

Tabela 9. Equações de regressão relacionando o peso médio (PM) e o número de frutos (NF) das produções extra, comercial e total com as doses de $\mathrm{N}$ aplicadas, sem e com matéria orgânica (MO), do experimento de outono/primavera

\begin{tabular}{|c|c|c|c|}
\hline MO (t/ha) & Característica & Equação de regressão & $\mathbf{R}_{2}$ \\
\hline & & Produção extra & \\
\hline 00 & PM (g/fruto) & $\hat{\mathrm{Y}}=129,556+0,0106052^{* *} \mathrm{X}$ & 0,7252 \\
\hline 8 & PM (g/fruto) & $\hat{\mathrm{Y}}=128,42+0,037294^{*} \mathrm{X}-0,0000309168^{*} \mathrm{X}^{2}$ & 0,9171 \\
\hline 0 & $\mathrm{NF}(\mathrm{n} \%$ ha $)$ & $\hat{Y}=369.605+11.878,4^{*} X^{0,5}-294,265^{*} X$ & 0,9793 \\
\hline \multirow[t]{2}{*}{8} & $\mathrm{NF}\left(\mathrm{n}^{\mathrm{o}} / \mathrm{ha}\right)$ & $\hat{\mathrm{Y}}=424.176+504,830^{* *} \mathrm{X}-0,464627^{\circ} \mathrm{X}^{2}$ & 0,8538 \\
\hline & & Produção comercial & \\
\hline 0 & PM (g/fruto) & $\hat{\mathrm{Y}}=112030+000980631^{\circ} \mathrm{X}$ & 0,5710 \\
\hline 8 & PM (g/fruto) & $\hat{\mathrm{v}}=109816+0.0640764^{* *} \mathrm{Y}-00000609408^{* *} \mathrm{X}^{2}$ & 0,9492 \\
\hline 0 & $\mathrm{NF}\left(\mathrm{n}^{\mathrm{o}} / \mathrm{ha}\right)$ & $\hat{\mathrm{Y}}=527.219+12.821 .5^{* * *} \mathrm{X}^{0,5}-302.19^{* *} \mathrm{X}$ & 0,9151 \\
\hline 8 & $\mathrm{NF}\left(\mathrm{n}^{\mathrm{o}} / \mathrm{ha}\right)$ & $\begin{aligned} \hat{\mathrm{Y}}= & 640.530+56,9795^{\circ} \mathrm{X} \\
& \text { Produção total }\end{aligned}$ & 0,7135 \\
\hline 0 & $\mathrm{PM}$ (g/fruto) & $\hat{\mathrm{Y}}=\overline{\mathrm{Y}}=101,15$ & $\underline{-}$ \\
\hline 8 & PM (g/fruto) & $\hat{\mathrm{Y}}=95,5141+0,0671385^{* *} \mathrm{X}-0,0000683870^{* *} \mathrm{X}^{2}$ & 0,8683 \\
\hline & $\mathrm{NF}\left(\mathrm{n}^{\circ} / \mathrm{ha}\right)$ & $\hat{\mathrm{Y}}=707.929+22.601,8^{* * *} \mathrm{X}^{0,5}-501,041^{* *} \mathrm{X}$ & \\
\hline 0 & 8 & $\mathrm{NF}\left(\mathrm{n}^{\circ} / \mathrm{h} \hat{a}\right)=890.544+140,486^{*} \mathrm{X}$ & \\
\hline
\end{tabular}

o, ***e,***: Significativos a $10,5,1$ e $0,1 \%$ de probabilidade, respectivamente, pelo teste $t$.

Tabela 10. Produção de frutos extra AA, extra A, médio extra e não-comerciais em função das doses de nitrogênio aplicadas e da adubação orgânica do experimento de outono/primavera

\begin{tabular}{lcrc}
\hline & & \multicolumn{2}{c}{ Adubação orgânica (t/ha) } \\
\cline { 1 - 1 } Koses de N & Classes de frutos & $\mathbf{0}$ & $\mathbf{8}$ \\
\cline { 3 - 4 } & & 3.519 & Produção de frutos (kg/ha) \\
\cline { 3 - 4 } 0 & & 31.496 & 5.202 \\
0 & Extra AA & 13.103 & 36.108 \\
0 & Extra A & 11.263 & 14.657 \\
93,5 & Médio extra & 2.945 & 16.842 \\
93,5 & Não-comercial & 40.131 & 3.499 \\
93,5 & Extra AA & 18.241 & 40.962 \\
93,5 & Extra A & 15.456 & 18.140 \\
187,0 & Médio extra & 5.829 & 14.202 \\
187,0 & Não-comercial & 6.421 \\
187,0 & Extra AA & 16.567 & 44.174 \\
187,0 & Extra A & 20.330 & 15.129 \\
& Médio extra & 6.381 & 20.703 \\
374,0 & Não-comercial & 45.929 & 7.527 \\
374,0 & Extra AA & 15.257 & 55.869 \\
374,0 & Extra A & 21.686 & 16.516 \\
748,0 & Médio extra & 7.352 & 21.207 \\
748,0 & Não-comercial & 41.913 & 8.211 \\
748,0 & Extra AA & 14.456 & 45.114 \\
748,0 & Extra A & 18.936 & 16.348 \\
\hline
\end{tabular}

Rev. Ceres, Viçosa, v. 57, n.2, p. 2 63-273, mar/abr, 2010 
campo, do modo de aplicação da água, do adubo nitrogenado, de fertirrigação e da adubação a lanço.

\section{Experimento de outono/primavera}

O peso médio dos frutos classificados como comercial e extra nos dois níveis de adubação orgânica foi aumentado com maior dose de N (Tabela 9). Sharma et al. (1999), trabalhando com híbridos de tomateiro, na India, também observaram aumento no peso médio dos frutos com o aumento de $\mathrm{N}$ no solo. A aplicação de $\mathrm{N}$ também aumentou os números total, comercial e extra de frutos sem ou com adição de matéria orgânica (Tabela 9). He et al. (1999), trabalhando com tomateiro cv. Momotaro, constataram que o número de frutos por cacho correlacionou-se significativa e positivamente com a concentração de $\mathrm{N}_{-} \mathrm{NO}_{3}$ - na seiva do pecíolo da folha imediatamente oposta ao cacho. Os resultados encontrados no presente experimento deixam claro que o $\mathrm{N}$ aumenta a produção do tomateiro não apenas devido ao aumento no peso médio de frutos comerciais como também no número desses frutos.

Os frutos extra AA, extra A e médio extra tiveram, respectivamente, pesos médios de 176,18; 143,63; e 106,47 g/ fruto sem adição de matéria orgânica ao solo e de 202,4; 141,92; e 106,67 g/fruto com adição. Tais valores foram superiores aos encontrados por Fayad (1998) nos mesmos local e época do presente experimento, com o mesmo cultivar (Santa Clara). Sem adição de matéria orgânica, as produções das três classes foram afetadas, já com adição apenas as produções extra AA e extra A. Sem adição de matéria orgânica, a produção extra AA aumentou linearmente com as doses de $\mathrm{N}$, e os valores máximos das produções extra A e extra foram 46,76 e 16,89 t/ha com as doses 552,8 e $233,4 \mathrm{~kg} / \mathrm{ha}$ de $\mathrm{N}$, respectivamente. Com a adição de 8 t/ha de matéria orgânica ao solo, a produção de frutos extra AA aumentou linearmente com as doses de $\mathrm{N}$ e a produção extra $\mathrm{A}$ alcançou o valor máximo de $53,86 \mathrm{t} /$ ha com a dose $531,8 \mathrm{~kg} /$ ha de N (Figura 2).

Guimardes (1998), trabalhando com o híbrido de tomateiro Débora-Plus em condições de campo, porém com fertirrigação por gotejamento, obteve produção máxima para os frutos do tipo extra A menor do que as encontradas no presente experimento (40,27 t/ha), porém com dose de $\mathrm{N}$ menor (122 kg/ha). O tipo de irrigação utilizado no presente experimento (por superfície) pode ter diminuídoa eficiência da adubação nitrogenada, uma vez que, possivelmente, aumentaram-se as perdas de $\mathrm{N}-\mathrm{NO}_{3}$ por lixiviação e também por escorrimento superficial, visto queo terreno era inclinado. Esse fato refletiu diretamente na produtividade dos frutos de melhor qualidade. Os frutos das classes extra AA e extra A são os mais procurados nos mercados mais exigentes, propiciando vendas rápidas e de melhor prego, garantindo maiores lucros ao tomaticultor, que tem os custos da colheita, das caixas, da comercialização e do transporte iguais para os frutos de diferentes classes. A maior proporção da produção extranas duas doses de matéria orgânica foi dos frutos extra A(Tabela 10).

As percentagens de frutos comercialmente desclassificáveis em todas as doses de $\mathrm{N}$, nos dois níveis de matéria orgânica (Tabela 11), foram, aparentemente, bem menores do que aquelas observadas no experimento de primavera/verão (Tabela 8), o que se deve às condições climáticas da época (Tabela 2), as quais contribuíram para o menor desenvolvimento de pragas e doenças. Os principais fatores responsáveis pela desclassificação de frutos foram os defeitos causados pelos ataques de broca e a ocorrência de Alternaria solani. Também ocorreram podridão apical, rachaduras e frutos de diâmetro menor que $40 \mathrm{~mm}$ ou frutos refugos, além de outras anomalias (Tabela 11).
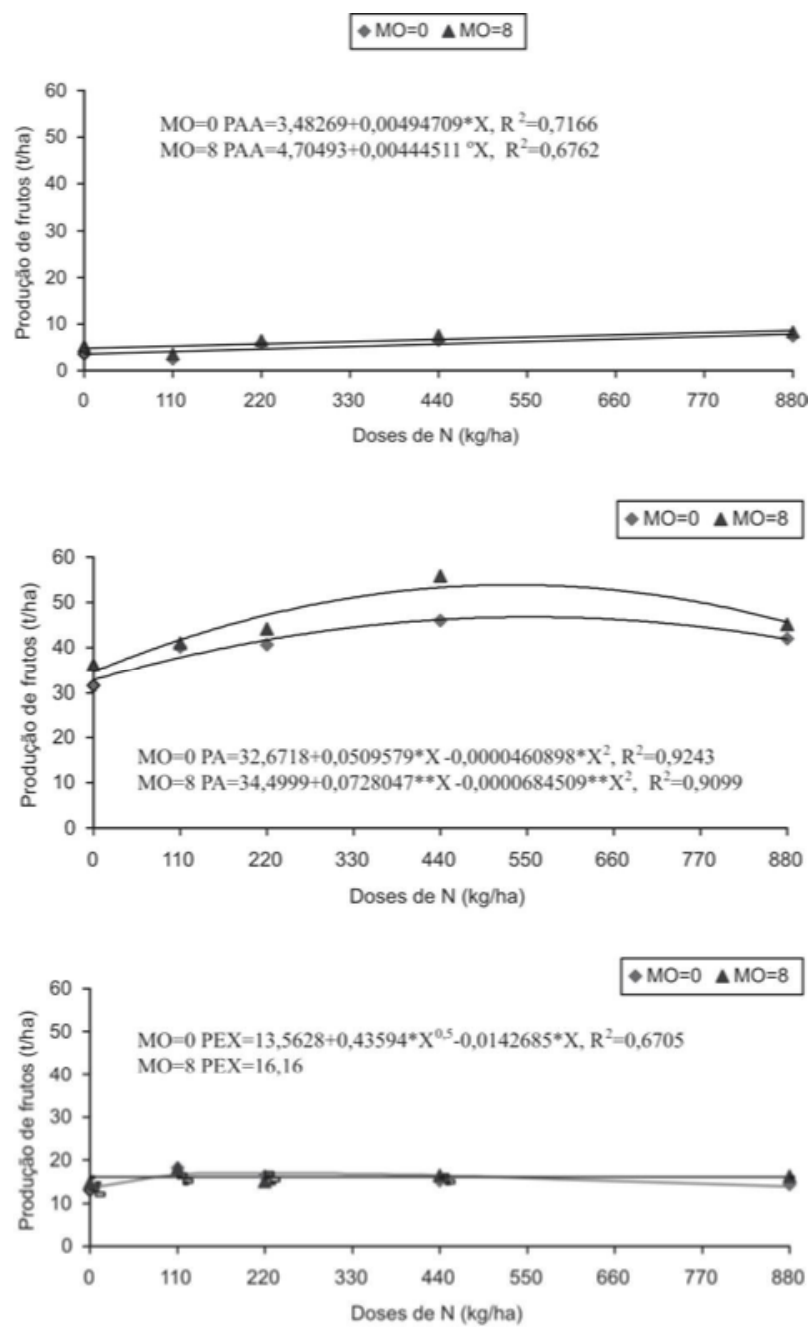

o, $\bullet$ e $\bullet$ Significativos a 10,5 e $1 \%$ de probabilidade, respectivamente, pelo teste t.

Figura 2. Produções de frutos extra AA (PAA), extra A (PA) e extra $(\mathrm{PEX})$ em função das doses de nitrogênio $(\mathrm{N})$ e da matéria orgânica (MO) do experimento de outono/primavera. 
Tabela 11. Valores absolutos e relativos das produções total e não-comercial de frutos de tomate em função das doses de $\mathrm{N}$ e da adubação orgânica (MO), do experimento de outono/primavera

\begin{tabular}{|c|c|c|c|c|c|c|c|c|c|c|}
\hline \multirow{3}{*}{ Produção de frutos } & \multicolumn{10}{|c|}{ Doses de Nitrogênio (kg/ha) } \\
\hline & \multicolumn{2}{|c|}{$\begin{array}{l}\mathbf{0 , 0} \\
\mathrm{MO}\end{array}$} & \multicolumn{2}{|c|}{$\begin{array}{l}93,5 \\
\text { MO }\end{array}$} & \multicolumn{2}{|c|}{$\begin{array}{l}187,0 \\
\text { MO } \\
\end{array}$} & \multicolumn{2}{|c|}{$\begin{array}{l}\text { 374,0 } \\
\text { MO }\end{array}$} & \multicolumn{2}{|c|}{$\begin{array}{c}748,0 \\
\text { MO }\end{array}$} \\
\hline & 0 & 8 & 0 & 8 & 0 & 8 & 0 & 8 & 0 & 8 \\
\hline & \multicolumn{10}{|c|}{ t/ha } \\
\hline Total & 69,8 & 87,0 & 89,2 & 88,6 & 94,6 & 69,8 & 87,0 & 89,2 & 88,6 & 94,6 \\
\hline Não-comercial & 11,2 & 16,9 & 15,4 & 14,1 & 20,3 & 11,2 & 16,9 & 15,4 & 14,1 & 20,3 \\
\hline - Podridão-apical & 0,6 & 0,4 & 0,9 & 0,7 & 2,1 & 0,6 & 0,4 & 0,9 & 0,7 & 2,1 \\
\hline - Broca & 1,9 & 2,9 & 1,1 & 1,9 & 2,5 & 1,9 & 2,9 & 1,1 & 1,9 & 2,5 \\
\hline - Rachaduras & 0,4 & 0,7 & 0,9 & 0,5 & 1,8 & 0,4 & 0,7 & 0,9 & 0,5 & 1,8 \\
\hline - Alternaria solani & 4,3 & 6,6 & 6,6 & 5,9 & 7,3 & 4,3 & 6,6 & 6,6 & 5,9 & 7,3 \\
\hline - Refugos & 0,4 & 0,7 & 0,4 & 0,5 & 0,5 & 0,4 & 0,7 & 0,4 & 0,5 & 0,5 \\
\hline \multirow[t]{2}{*}{ - Outros } & 3,6 & 5,6 & 5,5 & 4,6 & 6,1 & 3,6 & 5,6 & 5,5 & 4,6 & 6,1 \\
\hline & \multicolumn{10}{|c|}{$\% 1$} \\
\hline Total & 100 & 100 & 100 & 100 & 100 & 100 & 100 & 100 & 100 & 100 \\
\hline Não-comercial & 16,2 & 19,4 & 17,2 & 16,0 & 21,3 & 16,2 & 19,4 & 17,2 & 16,0 & 21,3 \\
\hline - Podridão-apical & 0,9 & 0,5 & 1,0 & 0,8 & 2,2 & 0,9 & 0,5 & 1,0 & 0,8 & 2,2 \\
\hline - Broca & 2,7 & 3,3 & 1,2 & 2,1 & 2,6 & 2,7 & 3,3 & 1,2 & 2,1 & 2,6 \\
\hline - Rachaduras & 0,6 & 0,8 & 1,0 & 0,6 & 1,9 & 0,6 & 0,8 & 1,0 & 0,6 & 1,9 \\
\hline - Alternaria solani & 6,2 & 7,6 & 7,4 & 6,7 & 7,7 & 6,2 & 7,6 & 7,4 & 6,7 & 7,7 \\
\hline - Refugos & 0,6 & 0,8 & 0,4 & 0,6 & 0,5 & 0,6 & 0,8 & 0,4 & 0,6 & 0,5 \\
\hline - Outros & 5,2 & 6,4 & 6,2 & 5,2 & 6,4 & 5,2 & 6,4 & 6,2 & 5,2 & 6,4 \\
\hline
\end{tabular}

'Em relação à produção total.

Os incrementos relativos nas produtividades resultantes da adubação nitrogenada (IRPAN) no experimento de outono/primavera foram 22,90 e 27,67 kg de frutos extra AA por kg de $\mathrm{N}$ aplicado nas doses 0 e 8 t/ha de matéria orgânica, respectivamente. As eficiências da adubação nitrogenada estão relativamente baixas, principalmente considerando que a época de condução do experimento, outono/primavera, propicia condições ao desenvolvimento do tomateiro. Guimarães (1998) encontrou valores de 59,8 e $35,7 \mathrm{~kg}$ de frutos extra AA/kg de $\mathrm{N}$ aplicado em tomateiros fertirrigados por gotejamento e por sulcos, respectivamente, no campo. Huett (1993) e Abdul-Baki et al. (1997) recomendam que o fertilizante nitrogenado sej a aplicado ao tomateiro via água de irrigação. Talvez a baixa eficiência possa estar relacionada, como no experimento anterior, ao modo de aplicação do fertilizante em cobertura (a lanço) e ao tipo de irrigação praticada (por superfície), além do fato de o experimento ter sido conduzido em campo, dificultando a realização dos tratos culturais, expondo as plantas e o solo à incidência das chuvas e expondo as plantas aos fitopatógenos. Além disso, o teor existente no solo foi suficiente para suprir grande parte do $\mathrm{N}$, conforme mostram as produtividades de frutos extra AA das testemunhas não adubadas com $\mathrm{N}$, sem e com matéria orgânica adicionada ao solo, 68,3 e 66,7\% das produtividades máximas, respectivamente.

\section{CONCLUSÕES}

O peso e o número de frutos comercializáveis de tomate por planta são aumentados com o aumento do nível de $\mathrm{N}$ no solo.

A percentagem de frutos comercialmente desclassificáveis é maior na primavera/verão do que no outono/ primavera.

A eficiência da adubação nitrogenada pelo tomateiro é maior no outono/primavera do que na primavera/verão.

Na primavera/verão a eficiência da adubação nitrogenada é maior quando o solo é pobre em matéria orgânica, já no outono/primavera, quando é rico.

\section{AGRADECIMENTOS}

Ao CNPq, à FAPEMIG e aos funcionários da Horta do Fundão da Universidade Federal de Viçosa, que viabilizaram a execução dos experimentos de campo.

\section{REFERÊNCIAS}

Abdul-Baki AA (1997) Teasdale JR \& Korcak RF Nitrogen requirements of fresh-market tomatoes on hairy vetch and black polyethylene mulch. HortScience, 32:217-221.

Adams P, Winsor GW \& Donald JD (1973) The effects of nitrogen, potassium, and sub-irrigation on the yield, quality and composition of single-truss tomatoes. Journal of Horticultural Science \& Biotechnology, 48:123-133. 
Atiyeh RM, Aracon N, Edwards CA \& Metzger JD (2000) Influence of earthworm-processed pig manure on the growth and yield of greenhouse tomatoes. Bioresource Technology, 75:175-180.

Bar-Tal A \& Pressman E (1996) Root restriction and potassium and calcium solution concentrations affect dry-matter production, cation uptake, and blossom-end rot in greenhouse tomatoes. Journal of the American Society for Horticultural Science, 121:649-655.

Belda 0RS, Fenlon JS \& Ho LC (1996) Salinity effects on the xylem vassels in tomato fruit among cultivars with different susceptibilities to blossom-end rot. Journal of Horticultural Science, 71:173-179.

Castellane PD (1988) Podridão apical em frutos do tomateiro. Jaboticabal, FUNEP, 39p.

CEASA (2000). Boletim informativo diário de preços. Belo Horizonte, Secretaria de Agricultura, 26p.

Dominí ME, Pino M de los A \& Bertolí M (1993) Nuevas variedades de tomate (Lycopersicon esculentum Mill.) para la epoca no optima. Cultivos Tropicales, 14:94-97.

Fayad JA (1998) Absorção de nutrientes, crescimento e produção do tomateiro cultivado em condições de campo e estufa. Dissertação de Mestrado. Universidade Federal de Viçosa, Viçosa. 81p.

Felipe EF \& Casanova OE (2000) Fertilización con nitrogeno, fosforo y potasio en tomate (Lycopersicon esculentum Mill.) en suelos de vegas del Rio Guarico. Revista Unellez de Ciencia y Tecnologia, 17:21-44.

Francis PB \& Cooper PE (1998) Rate and timing of nitrogen fertilization on yield and gross revenue of fresh market tomatoes following a winter legume cover crop. Journal of Vegetable Crop Production, 4:55-65.

Gomez-Lepe BE \& Ulrich A (1974) Influence of nitrate on tomato growth. Journal of the American Society for Horticultural Science, 99:45-49.

Guimarães TG (1998) Nitrogênio no solo e na planta, teor de clorofila e produção do tomateiro, no campo e na estufa, influenciados por doses de nitrogênio. Dissertação de Mestrado. Universidade Federal de Viçosa, Viçosa. 184p.

He YQ, Terabayashi S, Asaka T \& Namiki T (1999) Effect of restricted supply of nitrate on fruit growth and nutrient concentrations in the petiole sap of tomato cultured hydroponically. Journal of Plant Nutrition, 22:799-811.

Hohjo M, Kuwata C, Yoshikawa K \& Ito T (1995) Effects of nitrogen form, nutrient concentration and $\mathrm{Ca}$ concentration on the growth, yield and fruit quality in NFT-tomato plants. Acta Horticulturae, 369:145-152.
Huett DO (1993) Fertiliser nitrogen and potassium studies with Flora-Dade tomatoes grown with trickle irrigation and polyethylene mulch covered beds on Krasnozem soils. Australian Journal of Experimental Agriculture, 33:221-226.

Huett DO \& Dettmann EB (1988) Effect of nitrogen on growth, fruit quality and nutrient uptake of tomatoes grown in sand culture. Australian Journal of Experimental Agriculture, 28:391399.

Hunter DJ \& Tuivavalagi NS (1998) Effect of organic matter and frequent fertiliser applications on tomato production in a coralline soil. Journal of South Pacific Agriculture, 5:63-65.

Kirkby EA (1979) Maximizing calcium uptake by plants. Communications in Soil Science and Plant Analysis, 10:89114.

Quijada JS, Dumas Y \& Bonafous M (1992) Growth and development of young tomato plants under nitrogen deficiency. Acta Horticulturae, 301:159-164.

Rahman MA, Saha JHUK, Chowdhury AR \& Chowdhury MMU (1997) Growth and yield of tomato as influenced by fertilizers and manure. Annals of Bangladesh Agriculture, 6:71-74.

Salek RC, Almeida DL, Oliveira MF \& Penteado AF (1981) Efeito do esterco de galinha e sua associação com fertilizantes sobre a produção do tomateiro no município de Teresópolis-RJ. Niterói, PESAGRO-Rio. 3p. (Comunicado Técnico no 70).

Sam O \& Iglesias L (1994) Caracterizacion del proceso de floracionfructificacion en variedades de tomate en dos epocas de siembra. Cultivos Tropicales, 15:34-43.

Sharma KC, Singh AK \& Sharma SK (1999) Studies on nitrogen and phosphorus requirements of tomato hybrids. Annals of Agricultural Research, 20:399-402.

Singh AK \& Sharma JP (1999) Studies on the effect of variety and level of nitrogen on plant growth and development and yield of tomato hybrids (Lycopersicon esculentum Mill.). Annals of Agricultural Research, 20:502-503.

Supatra S, Mukherji S \& Sem S (1998) Seasonal effects on nitrogenous compounds in two crop plants. Environment and Ecology, 16:871-874.

Wilcox GE, Hoff JE \& Jones CM (1973) Ammonium reduction of calcium and magnesium content of tomato and sweet corn leaf tissue and influence of incidence of blossom-end rot of tomato fruit. Journal of the American Society for Horticultural Science, 98:86-89. 